https://doi.org/10.15407/ujpe64.2.143

V.E. CHECHKO, ${ }^{1,2}$ V.YA. GOTSULSKIY, ${ }^{3}$ T.V. DIIEVA ${ }^{4}$

${ }^{1}$ I.I. Mechnikov National University of Odesa, Chair of Theoretical Physics and Astronomy

(42, Pasteur Str., Odesa 65082, Ukraine)

2 I.I. Mechnikov National University of Odesa, Scientific and Research Institute of Physics

(27, Pasteur Str., Odesa 65082, Ukraine; e-mail: AstandPPWT@ukr.net)

${ }^{3}$ I.I. Mechnikov National University of Odesa, Chair of General and Chemical Physics

(2, Dvoryans'ka Str., Odesa 65000,Ukraine; e-mail: vygot@onu.edu.ua)

${ }^{4}$ Institute of Stomatology and Oral Surgery, National Academy of Medical Sciences of Ukraine

(11, Rishel'evska Str., Odesa 65026, Ukraine; e-mail: lenkapenkaaaaa@gmail.com)

\title{
QUALITATIVE ANALYSIS OF CLUSTERING IN AQUEOUS ALCOHOL SOLUTIONS. II
}

\begin{abstract}
Specific features of the clustering in aqueous solutions of monoatomic alcohols have been discussed. Main attention is focused on details of the clustering in water-ethanol solutions. The clustering degree is supposed to depend on the nteraction between ethanol and water molecules, as well as on the ordering degree of the H-bond network in water, which changes with the temperature and concentration of the alcohol. The elementary cluster volume is assumed to be smaller than the sum of the molecular volumes of components that form this cluster. The clustering degree in aqueous solutions of methanol and ethanol and its concentration and temperature dependences are determined.
\end{abstract}

Ke ywords: solutions, water, monoatomic alcohols, elementary clusters, singular point.

\section{Introduction}

It is well known that the properties of aqueous solutions of monoatomic alcohols differ drastically from the properties of ideal solutions [1-3]. This difference manifests itself in such physical properties as the intensity of molecular light scattering in a vicinity of the singular point of the solution [4-6], adiabatic compressibility[7], and heat capacity [8], in the emergence of anomalously large relaxation times [3,9], and even in the behavior of the simplest thermodynamic parameter of the system, its contraction (a decrease in the volume at the solution formation) [10-14]. From the standpoint of the theory of molecular structure, all those and other peculiarities in the behavior of solutions [15] are a result of clustering processes running in them.

The first clear systematic ideas about the role of clusters in the behavior of solution properties were formulated by D.I. Mendeleev about 150 years ago [16]. Later, those concepts were developed and formulated more accurately. In particular, it was found

(C) V.E. CHECHKO, V.YA. GOTSULSKIY,

T.V. DIIEVA, 2019

ISSN 2071-0194. Ukr. J. Phys. 2019. Vol. 64, No. 2 in works [12-14] that the concentration dependences of the contraction corresponding to different experimental temperatures mutually intersect in a vicinity of the singular point of the aqueous ethanol solution corresponding to the alcohol molar fraction $x_{\mathrm{p}}=0.077$. The excess solution volume is characterized by an identical behavior $[17,18]$.

Under the conditions corresponding to the singular point of the aqueous ethanol solution, every alcohol molecule in the solution is surrounded by 25 26 water molecules, so that there are no unbound water molecules at all (see works $[3,14]$ ). In effect, there arises an ensemble of elementary clusters consisting of ethanol molecules and a monolayer of water molecules taken in the above-mentioned ratio. The elementary clusters form a dense system, in which every water molecule is actually connected with two neighbor ethanol molecules. This water molecule can be attributed to either of those ethanol molecules. As a result, there are on average 12-13 water molecules per one ethanol molecule. As was shown in works [3, 14], the uniform distribution of water molecules over the monolayers is thermodynamically unstable. Therefore, concentration fluctuations grow at the singular 
point, and there emerges a microscopically heterogeneous structure of the solution $[4,14,15,19,20]$.

It seems natural that if the ethanol concentration is low $\left(x \ll x_{\mathrm{p}}\right)$, every ethanol molecule should be connected with all water molecules from its closest neighborhood. But this assumption is not quite satisfactory, because it does not reflect the fact that the introduction of ethanol molecules into water requires some energy spent to change a local structure of water. Since the energy of interaction between a water molecule and an ethanol one only slightly exceeds the interaction energies between two water molecules and between two ethanol molecules (see works $[18,21]$ ), every ethanol molecule is bound to only a few of water molecules from its environment. In other words, only some of ethanol molecules participate in the formation of elementary clusters, whereas the others remain unclustered.

Note that we use the concept of hydrogen bonds here to interpret the results obtained. However, by this notion, we understand ordinary electrostatic interactions [22-27] giving rise to the same local tetrahedral structure of water that is observed experimentally [28]. In works [26,29], it was shown that the contributions associated with the overlapping of molecular electron shells do not exceed $15 \%$ of electrostatic contributions.

Furthermore, when using the notion of elementary cluster, we do not consider its specific structure anywhere. In addition, we believe that all elementary clusters possess different instantaneous structures within the time of their existence, which does not strongly exceed the lifetime of a hydrogen bond [30]. In effect, of principal importance are only the average number of water molecules entering the clusters and a circumstance that the formation of clusters leads to a certain decrease in the solution volume.

An important characteristic of an aqueous alcohol solution is the degree of its clustering $Z_{\mathrm{a}}(x, T)$, i.e. the ratio between the number of clustered alcohol molecules $N_{\mathrm{a}}^{(\mathrm{c})}$ and their total number $N_{\mathrm{a}}$ : $Z_{\mathrm{a}}(x, T)=N_{\mathrm{a}}^{(\mathrm{c})} / N_{\mathrm{a}}$. The behavior of the parameter $Z_{\mathrm{a}}(x, T)$ in the concentration interval $x_{\mathrm{p}}<x<1$ was determined in work [31].

In this work, the main attention is focused on the determination of two parameters: the clustering degree of water-ethanol solutions in the whole alcohol concentration interval and the reducible part of the excess solution enthalpy.

\section{Model Properties of Water-Alcohol Clusters}

When interpreting the properties of aqueous ethanol solutions, - first of all, this was the behavior of their contraction - D.I. Mendeleev [16] came to a conclusion that the mixing of solution components is accompanied by the hydration, i.e. the formation of molecular associates of definite compositions, namely, $\mathrm{C}_{2} \mathrm{H}_{5} \mathrm{OH}-12 \mathrm{H}_{2} \mathrm{O}, \mathrm{C}_{2} \mathrm{H}_{5} \mathrm{OH}-3 \mathrm{H}_{2} \mathrm{O}$, and $\mathrm{H}_{2} \mathrm{O}-3 \mathrm{C}_{2} \mathrm{H}_{5} \mathrm{OH}$. Later, Ya.V. Zeltser [32] found the values for the solution mixing heats corresponding to those compositions: 8.700, 3.077, and $0.934 \mathrm{~kJ} / \mathrm{mol}$, respectively.

It is more reasonable to recalculate those quantities per one particle: $3.57 k_{\mathrm{B}} T, 1.26 k_{\mathrm{B}} T$, and $0.383 k_{\mathrm{B}} T$. From whence, one can see that the molecular associates of the second and third types are unstable, because the corresponding mixing heats do not substantially exceed the energy of thermal motion, as it should be for more or less stable associates to be formed. Thus, to the right from the singular point, only the formation of associates of the first type $\left(\mathrm{C}_{2} \mathrm{H}_{5} \mathrm{OH}-12 \mathrm{H}_{2} \mathrm{O}\right)$ can be talked about.

This statement obviously contradicts the division of the concentration interval into a number of sections, which was proposed in work [32]. In particular, these are sections 1) $0 \leq x \leq 0.0766$, where the solution consists of associates of the first type $\left(\mathrm{C}_{2} \mathrm{H}_{5} \mathrm{OH}-12 \mathrm{H}_{2} \mathrm{O}\right)$ and water excess; 2$) 0.0766 \leq x \leq$ $\leq 0.25$, where the solution contains a mixture of associates of the first and second types $\left(\mathrm{C}_{2} \mathrm{H}_{5} \mathrm{OH}-12 \mathrm{H}_{2} \mathrm{O}\right.$ and $\left.\left.\mathrm{C}_{2} \mathrm{H}_{5} \mathrm{OH}-3 \mathrm{H}_{2} \mathrm{O}\right) ; 3\right) \quad 0.25 \leq x \leq 0.75$, where the solution contains a mixture of associates of the second and third types $\left(\mathrm{C}_{2} \mathrm{H}_{5} \mathrm{OH}-3 \mathrm{H}_{2} \mathrm{O}\right.$ and $\left.\mathrm{H}_{2} \mathrm{O}-3 \mathrm{C}_{2} \mathrm{H}_{5} \mathrm{OH}\right)$; the left end of this interval $(x=$ $=0.25$ ) coincides with the minimum of solution contraction; and 4) $0.75 \leq x \leq 1$, where the solutions includes hydrates of the third type $\left(\mathrm{H}_{2} \mathrm{O}-3 \mathrm{C}_{2} \mathrm{H}_{5} \mathrm{OH}\right)$ and an excess of alcohol.

As was done earlier [31], let us assume the solution volume to consist of the water and alcohol volumes $\left(V_{\mathrm{w}}^{(\mathrm{nc})}\right.$ and $V_{\mathrm{a}}^{(\mathrm{nc})}$, respectively) that do not belong to the cluster composition and the volume of clusters $V_{\text {wa }}^{(\mathrm{c})}$ :

$V_{\mathrm{s}}=V_{\mathrm{w}}^{(\mathrm{nc})}+V_{\mathrm{a}}^{(\mathrm{nc})}+V_{\mathrm{wa}}^{(\mathrm{c})}$.

An elementary cluster is supposed to include $z_{\mathrm{w}}$ water molecules and $z_{\mathrm{a}}$ alcohol molecules. The cluster composition will be characterized by the ratio $k=z_{\mathrm{w}} / z_{\mathrm{a}}$.

ISSN 2071-0194. Ukr. J. Phys. 2019. Vol. 64, No. 2 
To the right from the singular point, the number of water molecules is not enough for the formation of elementary clusters. As a result, the behavior of the parameter $k$ was modeled in work [31] by the expression

$k=\frac{1-x}{x} \quad\left(x>x_{\mathrm{p}}\right)$,

where it was assumed that $z_{\mathrm{a}} \sim x$ and $z_{\mathrm{w}} \sim 1-x$. To the left from the singular point, there is no water deficiency. Therefore, the value of the parameter $k$ in this interval should be assumed fixed and equal to its value at the singular point:

$k=\frac{1-x_{\mathrm{p}}}{x_{\mathrm{p}}} \quad\left(x \leq x_{\mathrm{p}}\right)$.

Accordingly, we adopt that, in the whole concentration interval, the cluster composition parameter varies as follows:

$k(x)= \begin{cases}(1-x) / x & \text { if } x>x_{\mathrm{p}}, \\ \left(1-x_{\mathrm{p}}\right) / x_{\mathrm{p}} & \text { if } x \leq x_{\mathrm{p}},\end{cases}$

which is a continuous function of the alcohol concentration. Since its derivative is discontinuous, it may result in the appearance of certain artifacts in a vicinity of the singular point.

If $N_{\mathrm{a}}$ alcohol molecules are added to $N_{\mathrm{w}}$ water molecules, some of the former will enter the composition of clusters. As a result, the volume occupied by unclustered water molecules will be equal to

$V_{\mathrm{w}}^{(\mathrm{nc})}=V_{\mathrm{w}}^{(0)}-v_{\mathrm{w}} k(x) Z_{\mathrm{a}}(x, T) N_{\mathrm{a}}$,

where $V_{\mathrm{w}}^{(0)}=v_{\mathrm{w}} N_{\mathrm{w}}$ is the initial water volume, $v_{\mathrm{w}}=m_{\mathrm{w}} / \rho_{\mathrm{w}}$ is the molecular water volume, $m_{\mathrm{w}}$ and $\rho_{\mathrm{w}}$ are the molecular weight and density of water, respectively, and $Z_{\mathrm{a}}(x, T)$ is the clustering degree. Note that the degree of solution clustering can also be determined in the framework of the chemical equilibrium theory [33]. However, for this purpose, one has to know the magnitude of the system energy variation at the formation of an elementary cluster. This approach will be considered in a separate work.

The volume of alcohol molecules beyond the clusters is determined by the expression

$V_{\mathrm{a}}^{(\mathrm{nc})}=\left[1-Z_{\mathrm{a}}(x, T)\right] v_{\mathrm{a}} N_{\mathrm{a}}$,

where $v_{\mathrm{a}}=m_{\mathrm{a}} / \rho_{\mathrm{a}}$, and $m_{\mathrm{a}}$ and $\rho_{\mathrm{a}}$ are the molecular mass and density of alcohol, respectively.

ISSN 2071-0194. Ukr. J. Phys. 2019. Vol. 64, No. 2
The volume $V_{\text {wa }}^{(\mathrm{c})}$ occupied by elementary clusters equals

$V_{\mathrm{wa}}^{(\mathrm{c})}=\frac{1}{x_{\mathrm{p}}} v_{\mathrm{c}} Z_{\mathrm{a}}(x, T) N_{\mathrm{a}}$,

where

$v_{\mathrm{c}}=\frac{m_{\mathrm{w}}\left(1-x_{\mathrm{p}}\right)+m_{\mathrm{a}} x_{\mathrm{p}}}{\rho_{\mathrm{c}}}$,

and $\rho_{\mathrm{c}}$ is the solution density at the singular point.

The clustering degree can be obtained from the solution density according to the equation

$\rho_{\mathrm{s}}=\frac{m_{\mathrm{w}}(1-x)+m_{\mathrm{a}} x}{V_{\mathrm{s}}}$,

where $V_{\mathrm{s}}=v_{\mathrm{w}}(1-x)-v_{\mathrm{w}} k(x) Z_{\mathrm{a}}(x, T) x+v_{\mathrm{a}}(1-$ $\left.-Z_{\mathrm{a}}(x, T)\right) x+\frac{1}{x_{\mathrm{p}}}$ is the total molar volume of the solution. Note that $\rho_{\mathrm{s}}$ is the experimentally measured quantity. Now, from Eq. (1), we can obtain a formula for the clustering degree $Z_{\mathrm{a}}(x, T)$ :

$Z_{\mathrm{a}}=\frac{x_{\mathrm{p}}}{x} \frac{\frac{m_{\mathrm{w}}(1-x)-m_{\mathrm{a}} x}{\rho_{\mathrm{s}}(x, T)}-v_{\mathrm{w}}(1-x)-v_{\mathrm{a}} x}{v_{\mathrm{c}}-v_{\mathrm{w}} k(x) x_{\mathrm{p}}-v_{\mathrm{a}} x_{\mathrm{p}}}$.

The excess volume of the solution is determined by the relation

$V^{E}=V_{\mathrm{s}}-V_{\mathrm{id}}$,

where $V_{\mathrm{s}}$ and $V_{\mathrm{id}}$ are the molar volumes of real and ideal solutions, respectively. One can make sure that, to the left from the singular point, $V^{E}$ looks like

$V^{E}=V_{\mathrm{p}}^{E} Z_{\mathrm{a}}(x, T) \frac{x}{x_{\mathrm{p}}}$,

where

$V_{\mathrm{p}}^{E}=v_{\mathrm{c}}-v_{\mathrm{w}}\left(1-x_{\mathrm{p}}\right)-v_{\mathrm{a}} x_{\mathrm{p}}=20.078 \mathrm{~cm}^{3}$

is the excess solution volume at the singular point of the aqueous ethanol solution $[12-14,34]$, and $v_{\mathrm{c}}, v_{\mathrm{w}}$, and $v_{\mathrm{a}}$ are the molar volumes of elementary clusters, water, and alcohol, respectively, at a temperature of $25{ }^{\circ} \mathrm{C}$.

Taking the results obtained in work [31] into account, the relation between the parameter $Z_{\mathrm{a}}(x, T)$ and the solution contraction $\varphi(x, T)$ is given by the formula

$Z_{\mathrm{a}}(x, T)=\frac{x_{\mathrm{p}}}{x} \frac{v_{\text {id }}(x, T)}{v_{\text {id }}\left(x_{\mathrm{p}}, T\right)} \frac{\varphi(x, T)}{\varphi\left(x_{\mathrm{p}}, T\right)}$,

where $v_{\text {id }}(x, T)$ is the molar volume of the ideal solution. 


\subsection{Clustering degree in aqueous ethanol solutions}

The results of corresponding calculations for $Z_{\mathrm{a}}(x, T)$ are shown in Fig. 1. One can see that, to the left from the singular point, the clustering degree of alcohol molecules monotonically increases with both the concentration and temperature. This fact absolutely correlates with the conclusions of works [35-37], in which it was shown that liquid water demonstrates quasicrystalline properties up to the characteristic temperature $T_{d} \approx(42 \pm 3)^{\circ} \mathrm{C}$. Near this temperature (at $\left.T=40{ }^{\circ} \mathrm{C}\right), Z_{\mathrm{a}}(x, T)$ approaches unity when starting from low ethanol concentrations (see Fig. 1). To the right from the singular point, the deficiency of water molecules, on the contrary, gives rise to a reduction of the alcohol molecule clustering degree with the temperature growth.

Here are some speculations concerning the results obtained. Our basic assumption consisted in that the aqueous ethanol solution can be regarded as a three-component solution including water and alcohol molecules and clusters. Elementary clusters are dynamic formations of alcohol and water molecules taken in a ratio of $1: 12$. The presence of clusters distinguishes real aqueous alcohol solutions from ideal ones. However, the clustering takes place at all concentrations.

\subsection{Clustering degree in aqueous methanol solutions}

The body of experimental data for the density of aqueous methanol solutions and its dependences on the concentration and temperature [38] allowed us to calculate the corresponding dependences of the parameter $Z_{\mathrm{a}}(x, T)$. In aqueous methanol solutions, the singular point is observed at the concentration $x_{\mathrm{p}}=0.165$ [12-14].

The concentration dependences of the parameter $Z_{\text {a }}$ for the water-methanol solutions at various temperatures are depicted in Fig. 2.

\section{Relation between the Clustering Degree and the Solution Mixing Enthalpy}

Similarly to the case of clustering, let us suppose that the solution enthalpy $H_{\mathrm{s}}$ can be presented as the sum

$H_{\mathrm{s}}=H_{\mathrm{w}}^{(\mathrm{nc})}-H_{\mathrm{a}}^{(\mathrm{nc})}-H_{\mathrm{wa}}^{(\mathrm{c})}$, where $H_{\mathrm{w}}^{(\mathrm{nc})}, H_{\mathrm{a}}^{(\mathrm{nc})}$, and $H_{\mathrm{wa}}^{(\mathrm{c})}$ are the enthalpies of unclustered (free) water and alcohol molecules and the clustered component, respectively. In the same way as in the case of contraction, we can obtain a relation between the reducible part $H^{(\varphi)}(x)$ of the excess enthalpy and its value at the singular point $H_{\mathrm{p}}^{E}$, namely,

$H^{(\varphi)}(x)=H_{\mathrm{p}}^{E} Z_{\mathrm{a}}(x, T) \frac{x}{x_{\mathrm{p}}}$,

where

$H_{\mathrm{p}}^{E}=H_{\mathrm{p}}-H_{\mathrm{w}}\left(1-x_{\mathrm{p}}\right)-H_{\mathrm{a}} x_{\mathrm{p}}=-285.796 \mathrm{~kJ} / \mathrm{mol}$

(see work [39]) is the solution enthalpy at the singular point, and $H_{\mathrm{w}}$ and $H_{\mathrm{a}}$ are the enthalpies of water and ethanol, respectively, at a temperature of $25^{\circ} \mathrm{C}$. Here, we assumed that, from the thermodynamic viewpoint, the excess enthalpy of a solution is determined by the bulk and thermal components,

$H^{E}=H^{(\varphi)}(x)+H^{(h)}(x)$,

where the first term corresponds to the bulk (reducible) enthalpy component, and the second one to the thermal component.

A comparison of formulas (3) and (5) brings us to a conclusion that the value of the reducible part of the excess enthalpy, which is considered as a function of the concentration, is proportional to the excess volume of the system,

$H^{(\varphi)}(x)=\alpha V^{E}$,

where $\alpha=H_{\mathrm{p}}^{E} / V_{\mathrm{p}}^{E}$. Changing to dimensionless quantities by normalizing the dimensional parameters by their values at the singular point,

$\widetilde{H}^{(\varphi)}=\frac{H^{E}}{H_{\mathrm{p}}^{E}}, \quad \widetilde{V}^{E}=\frac{V^{E}}{V_{\mathrm{p}}^{E}}$,

we can rewrite Eq. (6) in the form of the identity

$\widetilde{H}^{(\varphi)}(x)=\widetilde{V}^{E}(x)$.

A comparative behavior of $H^{E}(x)$ and $H^{(\varphi)}(x)$ is shown in Fig. 3. As one can see, to the right from the intersection point of curves 1 and $2\left(x=x^{\prime}\right)$ and to the left from the solution singular point $\left(x=x_{\mathrm{p}}\right)$, the reducible component of the excess enthalpy is lower than the experimental values of $H^{E}(x, T)$. This fact

ISSN 2071-0194. Ukr. J. Phys. 2019. Vol. 64, No. 2 


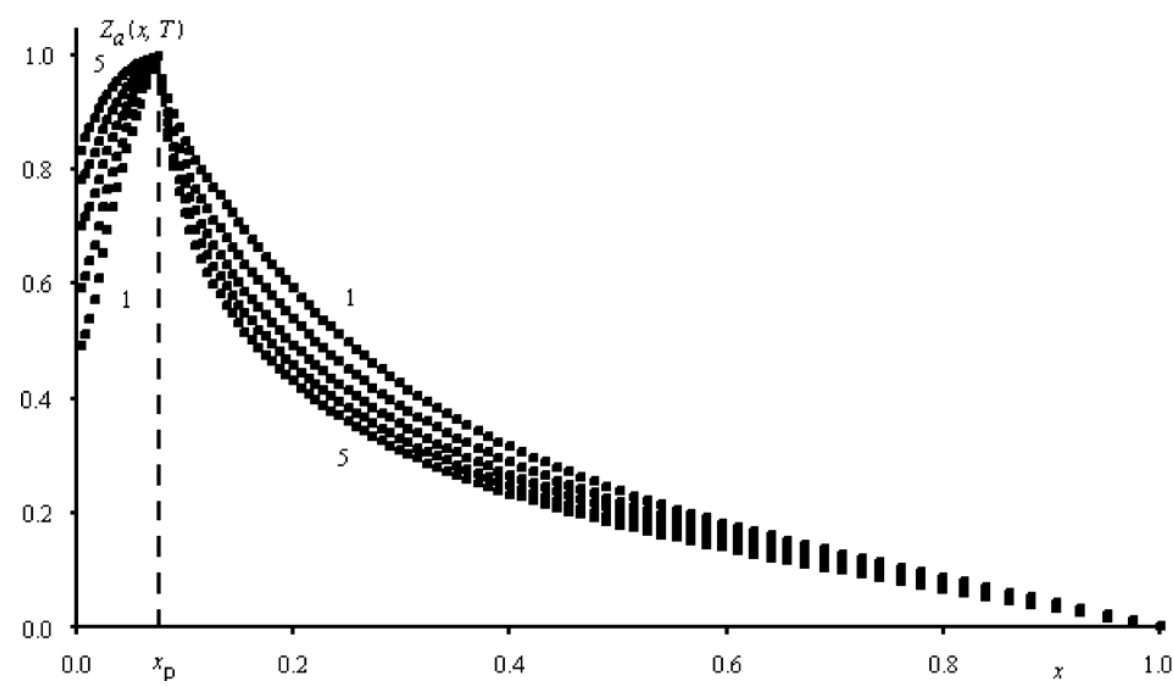

Fig. 1. Concentration dependences of the clustering degree of ethanol molecules in aqueous solutions at temperatures of 0 (1), 10 (2), 20 (3), 30 (4), and $40{ }^{\circ} \mathrm{C} \mathrm{(5).} \mathrm{The} \mathrm{curves} \mathrm{are} \mathrm{arranged} \mathrm{from} \mathrm{bottom} \mathrm{to} \mathrm{top} \mathrm{to} \mathrm{the} \mathrm{left} \mathrm{from} \mathrm{the} \mathrm{singular} \mathrm{point,} \mathrm{and} \mathrm{from}$ the top to bottom to the right from it. Experimental data were taken from work [34]. The dashed line marks the concentration position of the singular point $x_{\mathrm{p}}$

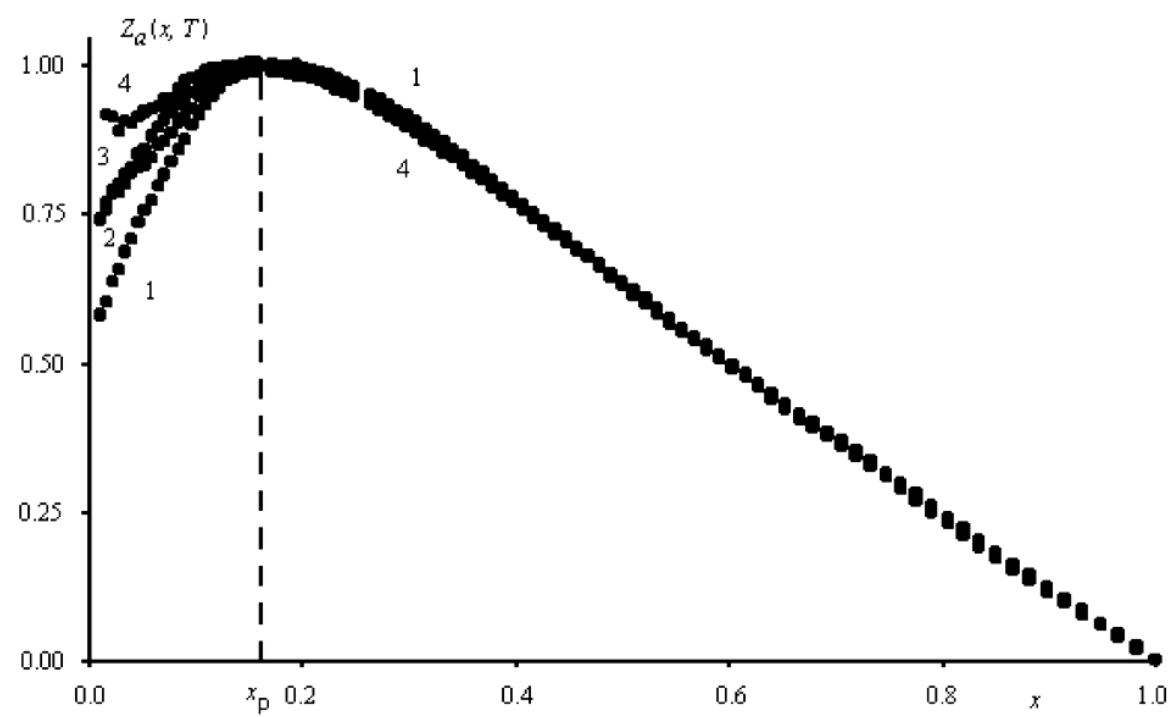

Fig. 2. Concentration dependences of the clustering degree of methanol molecules in aqueous solutions at temperatures of 0 (1), 10 (2), 20 (3), and $30{ }^{\circ} \mathrm{C}(4)$. The curves are arranged from bottom to top to the left from the singular point, and from the top to bottom to the right from it. Experimental data were taken from work [38]. The dashed line marks the concentration position of the singular point $x_{\mathrm{p}}$

means that the heat component of the enthalpy is expectedly positive. The situation is opposite between those two points. However, it may follow from the somewhat inaccurate determination of the reducible component near the singular point. As a result, the obtained match between the left and right sections of curve 2 in a vicinity of the singular point is not quite satisfactory.

\section{Discussion of the Results Obtained}

Our assumption that the clusters of only one type are formed may probably be somewhat oversimpli- 


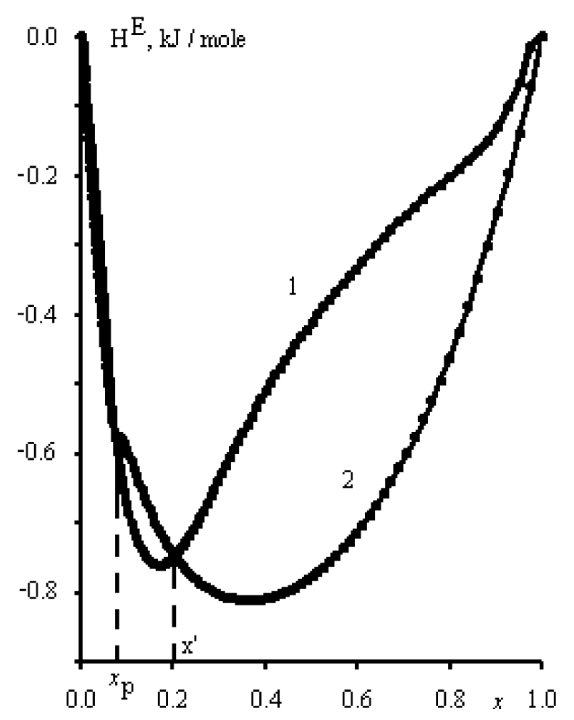

Fig. 3. Dependences of the excess enthalpy of aqueous ethanol solution (curve 1) and its reducible component (curve 2) on the solution concentration at a temperature of $25^{\circ} \mathrm{C}$. The excess enthalpy values were taken from works $[39,40]$. The dashed lines mark the concentration position of the singular point $x_{\mathrm{p}}$ and the intersection point of curves 1 and 2

fied. However, it is sufficient to describe the concentration and temperature dependences of the solution density and contraction [12-14].

Attention should be paid to the value of the cluster volume fraction

$x_{v}^{(\mathrm{c})}=\frac{V_{\mathrm{c}}}{V_{\mathrm{s}}}=\frac{v_{\mathrm{c}} Z_{\mathrm{a}}(x, T) x}{V_{\mathrm{s}}}$.

It is easy to verify that $x_{v}^{(\mathrm{c})} \approx 0.2 \div 0.22$ for the aqueous solutions of the first three alcohols in the homologous series of monoatomic alcohols. This value almost coincides with the specific volume of solid spheres [41] at the point, where the latter form an infinite percolation cluster. This fact allows us to interpret the singular point in the aqueous alcohol solutions as a point, where the alcohol molecules form an infinite percolation cluster.

A similar conclusion was also made in work [42], where the local structure of aqueous ethanol solutions was studied, by using the Raman light scattering and computer simulation. The cited authors noted that, in both those methods, the most significant change in the solution structure was observed at $x_{v}^{(p)} \approx 0.2$. The formation of spatially extended clusters by ethanol molecules explicitly manifests it- self when simulating the arrangement of large spheres in an environment composed of smaller spheres (see Fig. 12 in work [42]). The structure of the cluster depicted in that figure resembles the structure of a percolation cluster.

From our analysis of the clustering degree in aqueous alcohol solutions, it follows that $Z_{\mathrm{a}}(x, T)<1$ both to the left and to the right from their singular point. The equality $Z_{\mathrm{a}}\left(x_{\mathrm{p}}, T\right)=1$ is satisfied only at the solution singular point. In other words, the solutions can be considered clustered only at this point. To the left from the singular point, the clustering degree decreases, because water tries to preserve its ice-like structure. To the right from the singular point, the situation is inverse: it is the alcohol that tries to preserve its local structure. As a result, provided the same concentration, $Z_{\mathrm{a}}(x, T)$ increases to the left and decreases to the right from the singular point, as the temperature grows.

Note that the clustering degree in methanol is somewhat higher than that in ethanol. It is so because size of a methanol molecule is considerably smaller than the size of an ethanol molecule. Therefore, in a vicinity of the methanol molecule, its electric field affects the ordering in the environment more strongly. This speculation is supported by the diameters of methanol and ethanol molecules (3.89 and $4.41 \AA$, respectively $[43,44])$ and their dipole moments (1.706 and $1.68 \mathrm{D}$, respectively [45]).

The authors express their deep gratitude to Academician of the NAS of Ukraine L.A. Bulavin for his permanent attention to our work and the comprehensive assistance, inspiration, and encouragement for many years. We are also sincerely thankful to Prof. M.P. Malomuzh for the fruitful discussion of the results of this work and his help in writing this paper.

1. I. Prigogine. The Molecular Theory of Solution (NorthHolland, 1957) [ISBN: 5-229-00473-8].

2. A.A. Tager, L.V. Adamova. The volumes of mixing of liquids and their importance for the modern theory of solutions. Russ. Chem. Rev. 49, 325 (1980).

3. L.A. Bulavin, V.Ya. Gotsul'skii, N.P. Malomuzh, V.E. Chechko. Relaxation and equilibrium properties of dilute aqueous solutions of alcohols. Russ. Chem. Bull. Int. Ed. 65, 851, (2016).

4. M.F. Vuks. Light Scattering in Gases, Liquids, and Solutions (Leningrad State Univ., 1977) (in Russian). 
5. M.F. Vuks, L.V. Shurupova. Light scattering by solutions of propyl alcohols in water and heavy water. Zh. Strukt. Khim. 12, 712 (1971) (in Russian).

6. G.W. Beer, D.J. Jolly. Comments on "The scattering of light and phase transition in solution of tertiary butyl alcohol in water". Opt. Commun. 11, 150 (1974).

7. L.V. Lanshina, A.I. Abramovich. The compressibility, molecular light scattering, and structure of alcoholic solutions of benzene. Russ. J. Phys. Chem. A 79, 608 (2005).

8. M.A. Anisimov. Critical Phenomena in Liquid Crystals (CRC Press, 1988). (ISSN 0026-8941).

9. D. Subramanian, J.B. Klauda, J. Leys, M.A. Anisimov. Thermodynamic anomalies and structural fluctuations in aqueous solutions of tertiary butyl alcohol. Vestn. Sankt. Peterburg Univ. 4, 139 (2013).

10. E.S. Balankina. The influence of the size and packing of molecules on the volume-thermal properties of solutions. Russ. J. Phys. Chem. A 82, 1104 (2008).

11. E.S. Balankina. Theoretical Study of the Relationship "Packing Density-Thermodynamic Properties" in Condensed Systems. Dr. Sci. thesis (Tver'State Univ., 2010) (in Russian).

12. V.Ya. Gotsul'skii, N.P. Malomuzh, V.E. Chechko. Features of the temperature and concentration dependences of the contraction of aqueous solutions of ethanol. Russ. J. Phys. Chem. A 87, 1638 (2013).

13. V.Ya. Gotsul'skii, N.P. Malomuzh, M.V. Timofeev, V.E. Chechko. Contraction of aqueous solutions of monoatomic alcohols. Russ. J. Phys. Chem. A 89, 51 (2015).

14. V.Ya. Gotsulskiy, N.P. Malomuzh, V.E. Chechko. Particular points of water-alcohol solutions. Russ. J. Phys. Chem. A 89, 207 (2015).

15. V.M. Byakov, L.V. Lanshina, O.P. Stepanova, S.V. Stepanov. The nanoheterogeneous structure of aqueous solutions of $n$-propanol. Russ. J. Phys. Chem. A 83, 214 (2009).

16. D.I. Mendeleev. Solutions (Izd. Akad. Nauk SSSR, 1956) (in Russian).

17. K.N. Marsh, A.E.Richards. Excess volumes for ethanol + + water mixtures at $10-\mathrm{K}$ intervals from 278.15 to 338.15 K. Austral. J. Chem. 33, 2121 (1980).

18. G.C. Benson, O. Kiyohara, Thermodynamics of mixtures of nonelectrolytes. I. Excess volumes of water- $n$-alcohol mixtures at several temperatures. J. Solut. Chem. 9, 791 (1980).

19. Y. Koga. Solution Thermodynamics and its Application to Aqueous Solution (Elsevier, 2007).

20. G.C. Pimentel, A.L. McClellan. The Chemical Bond (W.H. Freeman, 1960).

21. N.P. Malomuzh, E.L. Slinchak. The cluster structure of dilute aqueous-alcoholic solutions and molecular light scattering in them. Russ. J. Phys. Chem. A 81, 1777 (2007).

22. N.D. Sokolov. Hydrogen bond. Usp. Fiz. Nauk 57, 205 (1955) (in Russian).
23. M.D. Dolgushin. On Universal Intermolecular Potential. Preprint ITF-7\%-83R (Institute of Theoretical Physics, Kyiv, 1977) (in Russian).

24. J.C. Berendsen, J.P.M. Postma, W.F. van Gunsteren J. Hermans. Interaction models for water in relation to protein hydration. In Intermolecular Forces. Edited by B. Pullman (Springer, 1981), p. 331.

25. R. L. Fulton, P. Perhacs. Sharing analysis of the behavior of electrons in some simple molecules. J. Phys. Chem. A 102, 8988 (1998).

26. N.P. Malomuzh, I.V. Zhyganiuk, M.V. Timofeev. Nature of H-bonds in water vapor. J. Mol. Liq. 242, 175 (2017).

27. D. Eisenberg, W. Kauzmann. The Structure and Properties of Water (Oxford Univ. Press, 2005).

28. V.P. Voloshin, E.A. Zheligovskaya, G.G. Malenkov et al. Structures of hydrogen bond networks and the dynamics of water molecules in condensed water systems. Zh. Ross. Khim. Obshch. 45, 31 (2001) (in Russian).

29. P.V. Makhlaichuk, N.P. Malomuzh, I.V. Zhyganiuk. Nature of hydrogen bond in water. Ukr. J. Phys. 57, 113 (2012).

30. G. G. Malenkov. Liquid water and ices: understanding the structure and physical properties. J. Phys.: Condens. Matter 21, 283101 (2009).

31. V.E. Chechko, V.Ya. Gotsulskyi. Qualitative analysis of clustering in aqueous alcohol solutions. Ukr. J. Phys. 63, 521 (2018).

32. Ya.V. Zeltser. Heat of mixing of ethanol-water solutions. Ferment. Spirt. Promyshl. 4, 11 (1966) (in Russian).

33. L.D. Landau, E.M. Lifshitz. Statistical Physics, Part 1 (Pergamon Press, 1980) [ISBN: 978-0-7506-3372-7].

34. Tables for the Determination of the Content of Ethyl Alcohol in Water-Alcohol Solutions (Izd. Standartov, 1972) (in Russian).

35. L.A. Bulavin, N.P. Malomuzh. Upper temperature limit for the existence of living matter. J. Mol. Liq. 124, 136 (2006).

36. A.I. Fisenko, N.P. Malomuzh. The role of the H-bond network in the creation of the life-giving properties of water. Chem. Phys. 345, 164 (2008).

37. L.A. Bulavin, N.P. Malomuzh, Dynamic phase transition in water as the most important factor in provoking protein denaturation in warm-blooded organisms. Fiz. Zhivogo 18, No. 2, 16 (2010) (in Russian).

38. CRC Handbook of Chemistry and Physics, 44th edition. Edited by C.D. Hodgman (CRC Press, 1962).

39. J.A. Boyne, A.G. Williamson. Enthalpies of mixing of ethanol and water at $25^{\circ}$ C. J. Chem. Eng. Data 12, 318 (1967).

40. R.F. Lama, B.C.-Y. Lu. Express thermodynamic property of aqueous alcohol solution. J. Chem. Eng. Data 10, 216 (1965). 
41. E.G. Birgin, F.N.C. Sobral. Minimizing the object dimensions in circle and sphere packing problems. Comput. Operat. Res. 35, 2357 (2008).

42. S. Banerjee, R. Ghosh, B. Bagchi. Structural transformations, composition anomalies and a dramatic collapse of linear polymer chains in dilute ethanol-water mixtures. $J$. Phys. Chem. B 116, 3713 (2012).

43. V.E.Chechko, V.Ya Gotsulsky, N.P. Malomuzh. Surprising thermodynamic properties of alcohols and water on their coexistence curves. J. Mol. Liq. 272, 590 (2018).

44. V.Ya. Gotsul'skii, N.P. Malomuzh, V.E. Chechko. Properties of hydrogen bonds in water and monohydric alcohols. Russ. J. Phys. Chem. A 92, 1516 (2018).

45. In Chemist's Handbook (Khimiya, 1966), Vol. 1, p. 963 (in Russian).

Received

Translated from Ukrainian by O.I. Voitenko
В.Є. Чечко, В.Я. Гочулъский, Т.В. Дієва

ЯКІСНИЙ АНАЛІЗ КЛАСТЕРИЗАЦЇ̈

В СПИРТОВО-ВОДНИХ РОЗЧИНАХ. II

$\mathrm{P}$ е $з$ ю м е

В роботі обговорюються особливості кластеризації в водних розчинах одноатомних спиртів. Основна увага фокусується на деталях кластеризації в розчинах вода-етанол. Передбачається, що ступень кластеризації залежить не тільки від характеру взаємодії між молекулами етанолу і води, а також і від ступеня впорядкування сітки водневих зв'язків у воді, що змінюється з температурою та концентрацією спиртів. Приймається, що об'єм елементарного кластера, виявляється меншим за сумарний молекулярний об'єм компонент, що утворюють цей кластер. Визначено ступень кластеризації у водних розчинах метанолу та етанолу в залежності від їх концентрацій та температур. 